\title{
Six new laureates in Canadian Medical Hall of Fame
}

$\mathrm{S}$ ix Canadian health care luminaries - three researchers, a clinician, a health care advocate and a world-famous poet - were inducted into the Canadian Medical Hall of Fame (CMHF) on Apr. 23 in Winnipeg. They join 101 laureates who have been recognized for their significant contributions to the improvement of health and health care in Canada and worldwide.

The CMHF is a national charitable organization that has honoured the accomplishments of Canadian medical professionals since 1994. An arms-length selection committee selects up to six laureates. Anyone can submit a nomination, said Lissa Foster, executive director of the CMHF, but it's important to nominate individuals who inspire people to take up careers in health services. "The selection committee can only choose from what they have in front of them, so the strength of the entire Hall is built on the quality and quantity of the nominations we get."

The six laureates for 2015:

Dr. Alan Bernstein has made important discoveries in stem cells, hematopoiesis and cancer research, with more than 225 published papers. Bernstein was the founding president of the Canadian Institutes of Health Research (CIHR) and the recipient of the 2008 Gairdner Wightman Award, the McLaughlin Medal from the Royal Society of Canada and many other awards. He is now the president and CEO of the Canadian Institute for Advanced Research.

Dr. Judith G. Hall has been a leader in pediatrics and genetics for more than 40 years and has published more than 325 papers. Her research has focused on genetic factors that affect children's growth. Hall has received more than 50 awards, including a fellowship in the Royal Society of Canada and the Order of Canada. She is now the head of pediatrics at the University of British Columbia (UBC) and BC Children's Hospital.

Dr. Bernard Langer is a pioneering surgeon in hepatobiliary/pancreatic (HPB) surgery who developed a leading
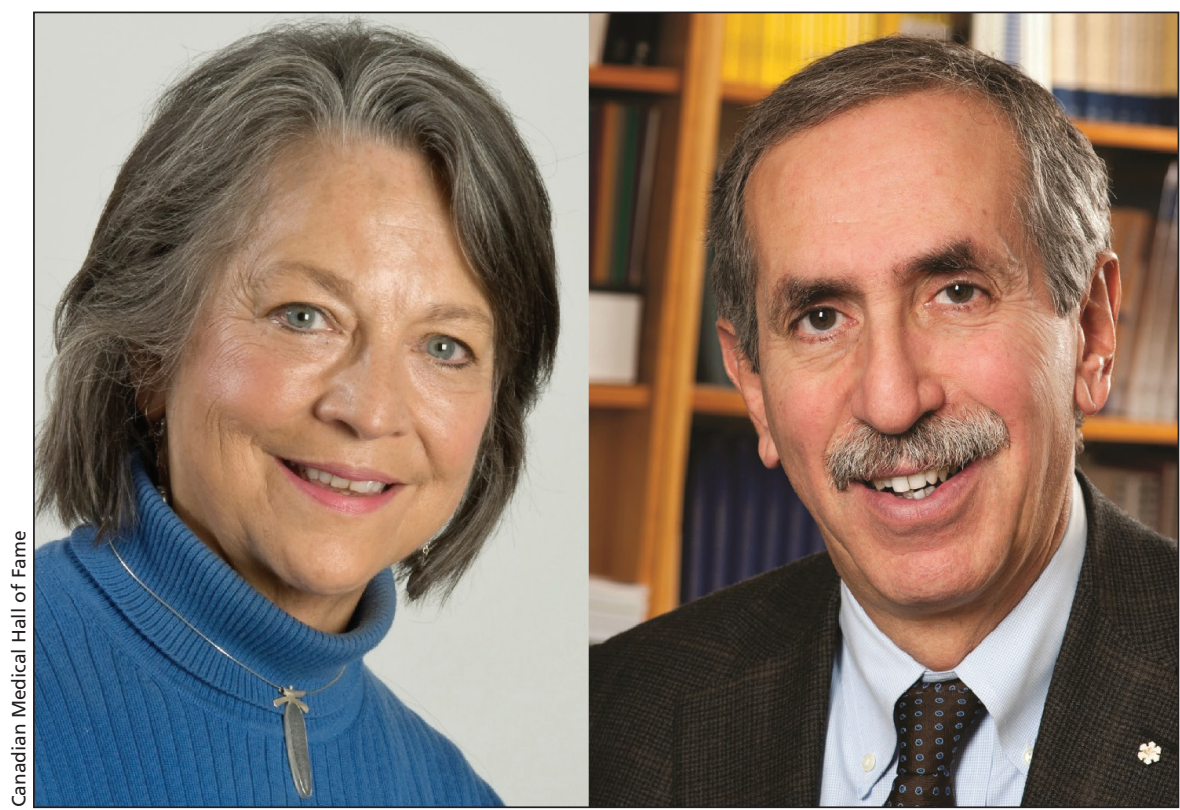

This year's inductees to the Canadian Medical Hall of Fame include Dr. Judith Hall and Dr. Alan Bernstein.

HPB and liver-transplant service when he was head of surgery at Toronto General Hospital. Langer set up the widely emulated Surgeon Scientist Program, a model for training academic surgeons. He was also instrumental in the creation of the Royal College of Physicians and Surgeons of Canada Clinician Investigator Program and the founding of the Canadian Patient Safety Institute.

The late Dr. John McCrae was an important contributor to the body of knowledge on diseases such as tuberculosis, scarlet fever, nephritis and lobar pneumonia. He coauthored the TextBook of Pathology for Students of Medicine. As a medical officer in World War $\mathrm{I}$, he wrote the iconic memorial poem "In Flanders Fields", which led to the use of the poppy as the symbol of remembrance. McCrae died of pneumonia in 1918 and was buried in Wimereux Cemetery with full military honours, close to the fields of Flanders.

Dr. Julio Montaner is internationally recognized for his contributions to new approaches to HIV and AIDS treatment. He led an international team that tested the viability of an innovative drug cocktail called highly active antiretroviral therapy, which helped to increase survival rates for people with HIV worldwide. Montaner also pioneered the idea of treatment as prevention, which was incorporated into WHO guidelines in 2013. He is a professor of medicine at UBC, founding codirector of the Canadian HIV Trials Network and director of the BC Centre for Excellence in HIV/AIDS.

Duncan G. Sinclair was instrumental to health care reform in Ontario, and his alternative-funding models for academic medicine are widely viewed as a benchmark for similar programs across Canada. Sinclair, whose undergraduate degree was in veterinary sciences, held numerous important posts in his career at the Medical Research Council, Canada Health Infoway and Queen's University in Kingston. At the latter, he became the first nonphysician to be vice-principal (Health Sciences) and dean of medicine. He continues to teach at the Queen's School of Policy Studies. — Martin Smith, CMAJ

CMAJ 2015. DOI:10.1503/cmaj.109-5050 